\title{
Prediction of left ventricular assist device implantation after repair of anomalous left coronary artery from the pulmonary artery
}

\author{
Frank Edwin, MD, ${ }^{\mathrm{a}, \mathrm{b}}$ Robin H. Kinsley, MD, ${ }^{\mathrm{a}}$ Alexander Quarshie, MD, MS, ${ }^{\mathrm{c}}$ and Peter R. Colsen, $\mathrm{MD}^{\mathrm{a}}$
}

Objective: We sought to determine the value of preoperative left ventricular function and cardiopulmonary bypass parameters in the prediction of left ventricular assist device implantation after repair of anomalous left coronary artery from the pulmonary artery.

\begin{abstract}
Methods: Multivariate logistic regression was performed to identify a predictive model for postrepair left ventricular assist device implantation using the records of 27 patients who underwent direct aortic implantation of anomalous left coronary artery from the pulmonary artery from 1994 to 2011.

Results: Seven patients required left ventricular assist device implantation. Patients in group $1(n=20)$ were successfully weaned from cardiopulmonary bypass. Patients in group $2(n=7)$ required left ventricular assist device as a bridge to recovery. The 2 groups were similar in age, weight, and body surface area. Six of the 7 patients $(85.7 \%)$ who required left ventricular assist device survived to hospital discharge. Hospital mortality was $3.7 \%$. In the univariate model, fractional shortening, ejection fraction, and aortic crossclamp time were significantly associated with left ventricular assist device implantation $(P=.026, .035, .031$, respectively). In the multivariate analysis, the aortic crossclamp time was the only significant independent predictor of left ventricular assist device implantation. Aortic crossclamp time and fractional shortening together accounted for $80.9 \%$ $(P<.001)$ of the variability in left ventricular assist device implantation and constituted the best predictive model: All patients requiring postrepair left ventricular assist device implantation had a fractional shortening less than $20 \%$ and an aortic crossclamp time greater than 56 minutes.
\end{abstract}

Conclusions: The fractional shortening and aortic crossclamp time together predict $80.9 \%$ of the variability in postrepair left ventricular assist device implantation after repair of anomalous left coronary artery from the pulmonary artery. When preoperative left ventricular dysfunction is severe (fractional shortening $<20 \%$ ), an aortic crossclamp time greater than 56 minutes is associated with a substantial risk of left ventricular assist device implantation after repair of anomalous left coronary artery from the pulmonary artery. (J Thorac Cardiovasc Surg 2012;144:160-5)

Chronic left ventricular (LV) ischemia, the primary physiologic derangement in anomalous left coronary artery from the pulmonary artery (ALCAPA), leads to depression of LV systolic function and is a significant surgical risk. LV systolic dysfunction in such patients is characterized by a depression in the contractile indices of fractional shortening (FS) and ejection fraction (EF). Accompanying these changes, increased LV end-diastolic dimension and varying degrees of mitral regurgitation (MR) are found. Severe ischemic LV dysfunction is common in ALCAPA, being present in 29 of 31 children undergoing primary repair in 1 report. ${ }^{1}$ Myocardial stunning occasioned by

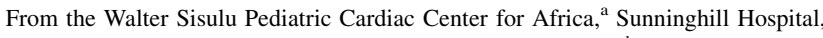
Johannesburg, South Africa; National Cardiothoracic Center, ${ }^{\mathrm{b}}$ Korle Bu Teaching Hospital, Accra, Ghana; and Morehouse School of Medicine, ${ }^{\mathrm{c}}$ Atlanta, Ga.

Disclosures: Authors have nothing to disclose with regard to commercial support.

Received for publication Aug 24, 2011; revisions received Nov 13, 2011; accepted for publication Dec 6, 2011; available ahead of print Dec 22, 2011.

Address for reprints: Frank Edwin, MD, National Cardiothoracic Center, Korle Bu Teaching Hospital, PO Box KB 591, Accra, Ghana (E-mail: fedwin68@yahoo. com).

$0022-5223 / \$ 36.00$

Copyright (c) 2012 by The American Association for Thoracic Surgery doi:10.1016/j.jtcvs.2011.12.004
}

cardiopulmonary bypass (CPB) required for surgical repair may further aggravate LV dysfunction in the immediate postoperative period. The creation of a dual coronary blood supply often results in substantial improvement in contractile function after ALCAPA repair with no need for postoperative mechanical circulatory support (MCS). In some children, however, profound postoperative contractile dysfunction requiring potentially injurious doses of inotropes or failure to wean from $\mathrm{CPB}$ occurs despite adequate repair. MCS in the form of a left ventricular assist device (LVAD) is required as a bridge to recovery in such patients.

Several studies have documented the successful use of an LVAD as a bridge to recovery in patients with ALCAPA, ${ }^{1-3}$ but predicting LVAD implantation in patients undergoing repair has not been well defined. Prediction is important as part of preoperative planning and parental counseling. Furthermore, such prediction may provide therapeutic targets to facilitate weaning of such patients from CPB. Nasseri and colleagues ${ }^{4}$ recently investigated the predictors of LVAD requirements after ALCAPA repair, but their study was limited to infants (aged $\leq 12$ months). In their report, the LV end-diastolic dimension was the most significant indicator of postrepair LVAD requirement. ${ }^{4}$ Azakie 


Abbreviations and Acronyms
$\begin{aligned} \text { ALCAPA }= & \text { anomalous left coronary artery from } \\ & \text { the pulmonary artery } \\ \text { ATP } & \text { adenosine triphosphate } \\ \text { CI } & =\text { confidence interval } \\ \text { CPB }= & \text { cardiopulmonary bypass } \\ \text { ECMO = extracorporeal membrane } & \text { oxygenation } \\ \text { EF } & =\text { ejection fraction } \\ \text { FS } & =\text { fractional shortening } \\ \text { LV } & =\text { left ventricular } \\ \text { LVAD }= & \text { left ventricular assist device } \\ \text { MCS }= & \text { mechanical circulatory support } \\ \text { MR } & =\text { mitral regurgitation } \\ \text { ROC } & =\text { receiver operating characteristic } \\ \text { XCT }= & \text { aortic crossclamp time }\end{aligned}$

and coworkers ${ }^{5}$ studied patients up to 31 years of age undergoing ALCAPA repair and reported that the median preoperative EF was significantly lower for patients who had extracorporeal membrane oxygenation (ECMO) compared with those who did not $(10 \%$ vs $40 \% ; P=.01)$. The mean preoperative predicted LV end-diastolic diameter was higher in the ECMO group (1.74 vs $1.34 \mathrm{~cm}$; $P=.027){ }^{5}$ Regression analyses were not performed in these studies.

The present study was prompted by our recent experience with a 32-month-old patient with ALCAPA and severe LV dysfunction who could not be weaned from CPB. With the use of logistic regression analysis, we sought to determine the predictive value of preoperative LV function and CPB conditions on LVAD implantation after ALCAPA repair in infants and children during our 17-year experience.

\section{PATIENTS AND METHODS}

Current repair of ALCAPA involves direct aortic implantation with cardioplegia delivered into the aorta and pulmonary artery to ensure adequate protection of both coronary territories. We included only patients who underwent direct aortic implantation as a means of revascularization of ALCAPA in the study period. Three patients (early in the experience) were excluded from the analysis for the following reasons: Takeuchi procedure (1), saphenous vein grafting of the left coronary artery (1), and cardioplegia delivery to the aortic root only (1).

We performed a retrospective analysis of all consecutive patients who underwent direct aortic implantation of ALCAPA by our group from January 1994 to June 2011. The diagnosis of ALCAPA was established on the basis of typical electrocardiography and findings on transthoracic echocardiogram. Coronary angiography was performed in doubtful cases (13 patients, $46.4 \%$ ). The anomalous left coronary artery took origin from the right pulmonary artery in 1 patient but from the root of the main pulmonary artery in all other patients. The LV function parameters selected for analysis included the FS, EF, LV end-diastolic dimension, and MR severity. The LV end-diastolic dimension was indexed to the body surface area for the analysis. The severity of MR was graded as grade 1 (nil or mild) or 2 (moderate or severe). CPB was assessed using the aortic crossclamp time (XCT) and total CPB time. The XCT measured represents that for a single crossclamp during the initial ALCAPA repair.

A total of 27 patients qualified for inclusion in the study. Patients were divided into 2 groups. Group $1(\mathrm{n}=20)$ included patients who were successfully separated from CPB after ALCAPA repair. Group $2(n=7)$ included patients who required LVAD because of failure to separate from CPB after ALCAPA repair.

Failure to wean from CPB after repair was defined as mean arterial pressure less than $45 \mathrm{~mm} \mathrm{Hg}$ and left atrial pressure greater than $16 \mathrm{~mm} \mathrm{Hg}$ despite the use of high-dose multidrug inotropic support and prolonged reperfusion.

\section{Surgical Technique}

All operations were performed through a median sternotomy with cannulation of the distal ascending aorta and a single venous drain. The technique of reimplantation was essentially similar in all patients, but the performance of the procedures by 4 different surgeons over a period of 17 years introduced some variability in the crossclamp and total bypass times. Our technique involves institution of hypothermic bypass $\left(25^{\circ} \mathrm{C}\right)$ and cold crystalloid (20 patients) (St Thomas Solution; Abbott Laboratories, Abbott Park, Ill) or cold blood cardioplegia (7 patients) infused simultaneously into the roots of the ascending aorta and main pulmonary artery after snaring the branch pulmonary arteries. We implant the ALCAPA into the corresponding aortic sinus to achieve minimal distortion of the anastomosis (ie, where the ALCAPA was originally meant to be). The pulmonary artery is reconstructed with autogenous pericardium while the patient is rewarmed. One patient aged 2.7 years underwent a Reed's annuloplasty repair of the mitral valve for severe MR and giant left atrium. Our technique and management of LVAD have been described. ${ }^{6}$ The important modification in patients with ALCAPA requiring LVAD is the insertion of an LV apical cannula for drainage to facilitate complete decompression of the LV.

\section{Statistical Analysis}

Descriptive statistics were calculated to summarize data. Normally distributed continuous variables are reported as mean \pm standard deviation. Continuous variables not normally distributed are presented as geometric mean $(95 \%$ confidence interval $[\mathrm{CI}])$ or range (median). Categoric variables are summarized and presented as frequencies and percentages. Differences in means of continuous and categoric variables were compared between groups by independent-samples Student $t$ test assuming equal variance. Variables not normally distributed were transformed on the natural $\log$ scale for the Student $t$ test. Categoric variables were compared between groups using the Pearson chi-square test.

Univariate logistic regression analysis was performed to assess associations between variables of interest and postrepair LVAD implantation. To identify predictors of postrepair LVAD implantation, risk factors showing statistically significant associations were further investigated using multivariate logistic regression. Collinearity among predictors was assumed if the variance inflation factor was greater than 10 and a relationship between predictor variables was known.

Receiver operating characteristic (ROC) curve analysis was used to determine predictive probabilities and the highest sensitivity/specificity for predicting postrepair LVAD implantation.

The results of logistic regression analyses are presented as odds ratios with $95 \%$ CI. All statistical tests were 2-sided. Statistical analyses were performed using IBM SPSS v19 (SPSS Inc, Chicago, Ill) and STATA SE v11.2 (StataCorp LP, College Station, Tex).

\section{RESULTS}

Group 1 included 20 patients, and group 2 included 7 patients. Groups 1 and 2 showed no statistically significant 
TABLE 1. Whole group data

\begin{tabular}{|c|c|c|c|}
\hline & Group 1 & Group 2 & $P$ value \\
\hline No. & 20 & 7 & \\
\hline Age $(\mathrm{mo})^{*}$ & $5.11(2.47-10.57)$ & $4.23(1.47-12.14)$ & .78 \\
\hline Weight $(\mathrm{kg})^{*}$ & $6.25(4.83-8.07)$ & $5.66(3.71-8.65)$ & .67 \\
\hline $\operatorname{BSA}\left(\mathrm{m}^{2}\right)^{*}$ & $0.32(0.26-0.39)$ & $0.31(0.22-0.43)$ & .83 \\
\hline FS $(\%)$ & $20.7 \pm 6.4$ & $13.1 \pm 5.9$ & .01 \\
\hline $\mathrm{EF}(\%)$ & $41.3 \pm 12.2$ & $28.1 \pm 11.4$ & .02 \\
\hline LV end-diastolic dimension index $\left(\mathrm{mm} / \mathrm{m}^{2}\right)$ & $129.1 \pm 43.6$ & $98.6 \pm 55.0$ & .12 \\
\hline MR grade (grade 2) & $10(50 \%)$ & $5(71.4 \%)$ & .47 \\
\hline Cardioplegia (blood) & $4(20 \%)$ & $3(43 \%)$ & .24 \\
\hline $\mathrm{XCT}(\min )^{*}$ & $50.93(44.74-57.98)$ & $77.53(53.30-112.78)$ & .005 \\
\hline CPB time $(\min )^{*}$ & $82.21(74.92-90.22)$ & $163.27(107.35-248.33)$ & $<.001$ \\
\hline
\end{tabular}

$B S A$, Body surface area; $F S$, fractional shortening; $E F$, ejection fraction; $L V$, left ventricular; $M R$, mitral regurgitation; $X C T$, aortic crossclamp time; $C P B$, cardiopulmonary bypass. *Variables not normally distributed (presented as geometric means, $95 \% \mathrm{CI}$ ).

differences in terms of age, weight, and body surface area (Table 1). Apart from infants, the total patient cohort included 4 older children aged 2.4 to 17 years (median 3.9 years) with an FS of $19.5 \%$ to $33.0 \%$ (median $20.5 \%$ ); an LVAD was required in 1 of these patients.

LV function between the 2 groups (Table 1) differed significantly in terms of FS $(20.7 \% \pm 6.4 \%$ vs $13.1 \% \pm$ $5.9 \%, P=.01)$ and $\mathrm{EF}(41.3 \% \pm 12.2 \%$ vs $28.1 \% \pm$ $11.4 \%, P=.02)$. Fourteen patients had an FS less than $20 \%, 7$ of whom required postrepair LVAD. The LV end-diastolic dimension (indexed to the body surface area), MR severity, and vehicle of cardioplegia showed no significant difference between the 2 groups (Table 1 ). As reflected in the total bypass time (Table 1), significantly prolonged reperfusion was allowed in group 2 to encourage separation from CPB. The prolonged bypass time in group 2 mainly resulted from attempted weaning from bypass and time spent implanting the LVAD; when the differences in XCT were accounted for, the initial bypass time during the actual repair was not significantly different between the 2 groups.

Seven patients required postrepair LVAD; 6 were successfully bridged to recovery and 1 died $(3.7 \%$ hospital mortality). The patient who did not survive was the only one to require ECMO because of postoperative respiratory failure from pulmonary infection. He died of intractable pulmonary sepsis after 228 hours of ECMO. The mean duration of LVAD support for the 7 patients was $84 \pm 66$ hours. One major complication was encountered during LVAD support-aortic cannula thrombosis necessitating termination of LVAD after 60 hours. The patient survived termination of mechanical support uneventfully.

\section{Logistic Regression Analysis}

After univariate logistic regression analysis, 3 independent variables (FS, EF, and XCT) were considered the most likely predictors (Table 2). The variance inflation factor for the 3 variables was 31.7 for FS and EF and 1.0 for XCT. In a linear regression model, the relationship between the EF and FS was determined to be

$$
\mathrm{EF}=1.85 \mathrm{FS}+3.34\left(R^{2}=0.965, P=.01\right) .
$$

On this basis and our preference for using FS as a measure of LV function, we excluded EF from the multivariate analysis of predictors noting that its predictive power will be accounted for almost entirely by the FS.

The FS and XCT were significantly associated with postrepair LVAD implantation $(P=.026$ and .031 , respectively $)$ in the univariate model (Table 2).

In the multivariate regression analysis (Table 3), only the XCT reached independent predictor status $(P=.051)$. The XCT alone accounted for a modest $44.2 \%$ of the proportion of variability in LVAD implantation (Table 2), but taken together with the FS in the multivariate analysis (Table 3), the explanatory value of the model improved significantly to $80.9 \%\left(R^{2}=0.809, \chi^{2}=21.67\right.$, degrees of freedom $=2$, $P<.001)$.

\section{Receiver Operating Characteristic Analyses}

By having determined that the best predictive model depended on a combination of the XCT and FS, ROC curve

TABLE 2. Univariate logistic regression analysis of left ventricular assist device implantation on selected variables

\begin{tabular}{lccc}
\hline \multicolumn{1}{c}{ Variable } & OR $(\mathbf{9 5} \% \mathbf{C I})$ & $\boldsymbol{P}$ value & $\boldsymbol{R}^{2}$ (Nagelkerke) \\
\hline FS $(\%)$ & $0.81(0.67-0.98)$ & .026 & 0.342 \\
EF $(\%)$ & $0.89(0.81-0.99)$ & .035 & 0.328 \\
LV end-diastolic & $1.00(0.98-1.03)$ & .79 & 0.00 \\
$\quad$ dimension index & & & \\
$\quad\left(\mathrm{mm} / \mathrm{m}^{2}\right)$ & & & \\
XCT $(\mathrm{min})$ & $1.09(1.01-1.18)$ & .031 & 0.442 \\
Age $(\mathrm{mo})$ & $0.99(0.94-1.04)$ & .59 & 0.032 \\
Weight $(\mathrm{kg})$ & $0.95(0.78-1.16)$ & .64 & 0.018 \\
BSA $\left(\mathrm{m}^{2}\right)$ & $0.42(0.00-49.54)$ & .78 & 0.004 \\
\hline
\end{tabular}

$O R$, Odds ratio; $F S$, fractional shortening; $E F$, ejection fraction; $L V$, left ventricular; $X C T$, aortic crossclamp time; $B S A$, body surface area. 
TABLE 3. Multivariate logistic regression of left ventricular assist device on fractional shortening and aortic crossclamp time

\begin{tabular}{lcc}
\hline Variable & OR $(\mathbf{9 5} \% \mathbf{C I})$ & $\boldsymbol{P}$ value \\
\hline XCT $(\min )$ & $1.19(1.00-1.41)$ & .051 \\
FS $(\%)$ & $0.54(0.26-1.12)$ & .097 \\
\hline
\end{tabular}

$R^{2}$ for XCT and FS together $=0.0809(P<.001) . O R$, Odds ratio; $F S$, fractional shortening; $X C T$, aortic crossclamp time.

analysis was conducted to determine the threshold values for XCT and FS that optimize sensitivity and specificity for the prediction. Because the FS varied inversely with the probability of LVAD implantation, each FS observation was transformed to FS', where FS' $=100 \%-$ FS. The FS' was then plotted against the LVAD requirement for the ROC curve analysis.

The ROC curve analysis showed an FS' value of $80.25 \%$ (or FS of $19.75 \%$, approximated to $20 \%$ ) as the threshold for a sensitivity of $100 \%$ and a specificity of $55 \%$. The threshold XCT was 56 minutes $(100 \%$ sensitivity, 55\% specificity).

On the basis of these thresholds, the predicted probability of LVAD implantation for patients with severe LV dysfunction (FS $<20 \%$ ) increased from $16 \%$ at an XCT of 56 minutes to $86 \%$ at an XCT of 59 minutes (Figure 1).

\section{DISCUSSION}

\section{Predicting Left Ventricular Assist Device} Implantation After Anomalous Left Coronary Artery

\section{From the Pulmonary Artery Repair}

Previous authors ${ }^{4,5}$ have investigated predictors of postrepair LVAD implantation in patients with ALCAPA by assessing statistically significant differences in the mean values of predictors between patients who did and did not require MCS; logistic regression analysis was not used. Furthermore, the contribution of intraoperative events to the postoperative outcome was not investigated. Both of these concerns have been addressed in the current study seeking to identify preoperative and intraoperative predictors. In keeping with their findings, ${ }^{4,5}$ our study demonstrates the importance of preoperative LV function in predicting the need for MCS after ALCAPA repair. But, unlike the previous studies, ${ }^{4,5}$ the current study did not demonstrate the predictive value of the LV end-diastolic dimension; LV end-diastolic pressure measurements were not uniformly available in our patient cohort to allow analysis. As shown in the present study, strong collinearity exists between the FS and EF such that after accounting for 1 of these parameters, no additional predictive power is gained by the inclusion of the other in the predictive model.

The XCT emerged as the most significant independent predictor of LVAD implantation (odds ratio, 1.19; 95\% CI, $1.00-1.41 ; P=.05$ ) with a threshold value of $56 \mathrm{~min}-$ utes. For the whole group, the XCT alone explains $44.2 \%$

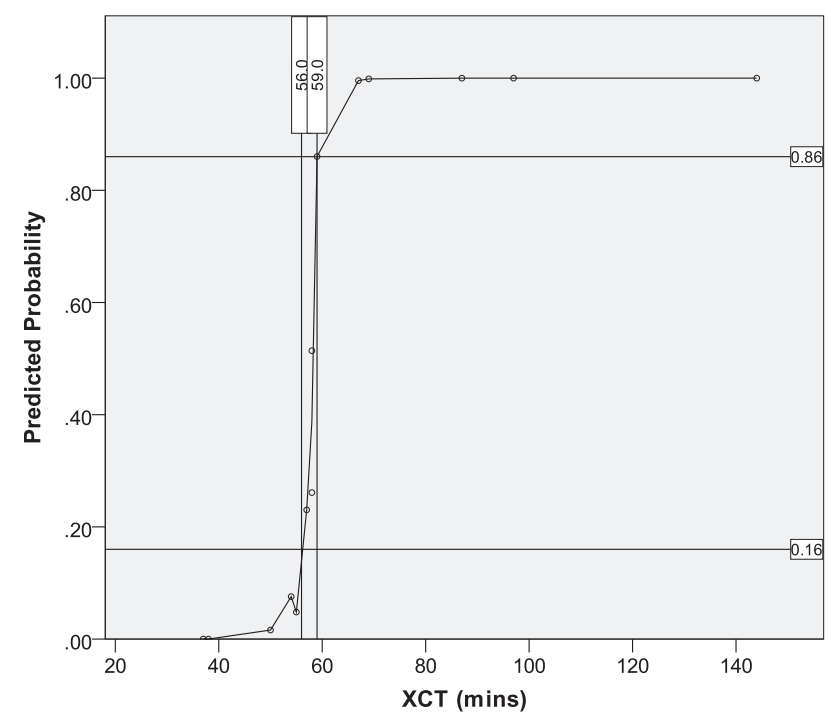

FIGURE 1. Influence of XCT on predicted probability of LVAD in severe LV dysfunction. $L V$, Left ventricular; $L V A D$, left ventricular assist device; $X C T$, aortic crossclamp time.

of the variability in LVAD requirement. However, the predictive value of the XCT is most important when taken together with the FS. Both together accounted for $80.9 \%$ of the variability in LVAD implantation $(P<.001)$. All patients who required postrepair LVAD had an FS less than $20 \%$; thus, we consider FS less than $20 \%$ as severe LV dysfunction.

\section{Severe Left Ventricular Dysfunction and Vulnerability to Ischemia}

Without the use of LVAD, patients with ALCAPA with severe LV dysfunction (FS $<20 \%$ ) are at increased risk for perioperative mortality. Vouhé and coworkers ${ }^{7}$ documented that the severity of preoperative LV dysfunction was the only incremental risk factor for mortality in 31 consecutive children with ALCAPA undergoing direct aortic implantation without an associated procedure: $31 \%$ mortality rate among patients with FS less than $20 \%$ versus $0 \%$ among patients with FS $20 \%$ or greater $(P=.03)$. In 39 consecutive patients undergoing dual coronary repair for ALCAPA, Lambert and coworkers ${ }^{8}$ found that total mortality was related only to the preoperative FS: $12 \%$ versus $24.8 \%(P<.05)$. Lange's group ${ }^{9}$ recently documented essentially similar findings. Our study is in agreement with the work of these investigators ${ }^{7-9}$ that an FS less than $20 \%$ in ALCAPA constitutes severe LV compromise and that substantial operative mortality may result without LVAD implantation.

From our results, the XCT best distinguishes those with severe LV dysfunction who ultimately require postrepair LVAD; the predicted probability of LVAD requirement in this group was sensitive to increases in XCT of more than 
56 minutes, reaching an estimated value of $86 \%$ at an XCT of 59 minutes (Figure 1). It seems that preoperative severe LV dysfunction in ALCAPA predisposes to the accelerated decline in contractile function beyond an ischemic time of 56 minutes. The XCT should be kept at less than 56 minutes in the repair of ALCAPA with severe LV dysfunction. Those without severe LV dysfunction do not seem to exhibit such a vulnerability to ischemia beyond 56 minutes. Modi and coworkers ${ }^{10}$ demonstrated a significant decline in the myocardial adenosine triphosphate (ATP) concentrations in both infants and children undergoing correction of congenital cardiac anomalies under CPB. The decline in ATP levels was strongly determined by the XCT time. Furthermore, infants and children who required a higher dose of postoperative inotropic support were those with a significantly greater degree of decline in myocardial ATP concentration. ${ }^{10}$ Intramyocardial ATP content has been shown to correlate with myocardial function ${ }^{11}$; ostensibly, in ALCAPA with severe LV dysfunction, XCTs exceeding 56 minutes promote a critical depletion of myocardial ATP to levels not immediately compatible with a spontaneous circulation.

\section{Intraoperative Myocardial Management and Left Ventricular Assist Device Requirement}

The predictive value of the XCT led us to speculate that the ischemic LV myocardium in patients with ALCAPA has a reduced tolerance for the myocardial stunning imposed by XCT and reperfusion. This tolerance seems to be critical at an XCT of 56 minutes in those with an FS less than $20 \%$. At this degree of depressed LV function, increasing degrees of myocardial stunning, reflected in a prolonged XCT, crosses a threshold that makes the probability of failure to wean from $\mathrm{CPB}$ and a requirement for LVAD implantation substantial. Better intraoperative myocardial management in terms of reducing crossclamp times and improved protection by cardioplegia would favorably alter this balance toward successful weaning from CPB. Backer and coworkers ${ }^{12}$ demonstrated the favorable outcome in terms of successful weaning from CPB by keeping the crossclamp time short. In a series of 16 patients, these workers achieved a mean XCT of $46 \pm 13$ minutes by removing the XCT after implantation of the anomalous left coronary artery before reconstruction of the pulmonary artery. ${ }^{12}$ There was no operative mortality, and as would be predicted from our model, none of their patients required postrepair LVAD.

As a corollary to the effect of the XCT, we expected that blood cardioplegia would favorably influence outcomes in terms of LVAD requirement. Blood cardioplegia is reported to offer superior myocardial protection compared with crystalloid cardioplegia. ${ }^{13}$ It is reported to have several benefits: enhanced oxygen-carrying capacity, active resuscitation, avoidance of reperfusion injury, and endogenous oxygen free radical scavenging among others. ${ }^{13}$ Belli and coworkers ${ }^{14}$ showed that blood cardioplegia may be advantageous in ALCAPA repair. These investigators assessed outcomes in 21 infants with ALCAPA with severe preoperative LV dysfunction (FS $<15 \%$ ) undergoing anatomic repair under normothermic CPB using intermittent antegrade normothermic blood cardioplegia for myocardial protection. All of their patients were successfully weaned from CPB after a mean XCT of $50 \pm 14.5$ minutes; LVAD was not necessary in any patient. There was 1 $(4.7 \%)$ early death due to sudden cardiac arrest 48 hours after successful weaning from mechanical ventilation. Other investigators ${ }^{15}$ have speculated that a strategy using both antegrade and retrograde blood cardioplegia, combined with appropriate postoperative inotropic support, may allow for favorable results without the need of MCS. We could not demonstrate that blood cardioplegia made a significant difference to outcomes in terms of LVAD requirement. We used cold antegrade blood cardioplegia without terminal warm blood cardioplegic reperfusion ("hot shot") in 4 patients in group 1 and 3 patients in group 2 . We could not demonstrate any significant difference in terms of LVAD requirement between cold blood and cold crystalloid cardioplegia. The explanation might be that although cold blood cardioplegia by itself is superior to cold crystalloid cardioplegia, it is not as good as cold blood cardioplegia with a hot shot. ${ }^{10}$ Seemingly, both the method and vehicle of cardioplegia delivery influence outcomes.

\section{Outcome of Left Ventricular Assist Device Use in Anomalous Left Coronary Artery From the Pulmonary Artery Repair}

Depending on the preoperative severity and institutional policy, the requirement for postoperative MCS after ALCAPA repair ranges from $25 \%$ to $36 \% .^{12}$ We used a veno-apical (right atrium and LV apex) cannulation technique with the Levitronix CentriMag (Levitronix LLC, Waltham, Mass) system and pump flow of $120 \mathrm{~mL} / \mathrm{kg}$ at normothermia using phosphorylcholine-coated bypass circuits with the Levitronix device. In our experience, an LVAD was required in 7 of 27 patients (26\%). Compared with the results of pediatric MCS for other indications, the results of MCS in the setting of ALCAPA are particularly encouraging. ${ }^{1-3,16} \mathrm{We}$ were able to wean and discharge 6 of 7 patients from MCS after ALCAPA repair, a success rate of $85.7 \%$.

Karl and coworkers ${ }^{17}$ reported on 115 pediatric patients with postcardiotomy heart failure supported with a ventricular assist device. The probability of weaning patients from the ventricular assist device was $66 \%$; the probability of hospital discharge was $43 \%$. Some investigators believe the excellent outcomes of LVAD in ALCAPA justify aggressive therapy regardless of the status of the LV. ${ }^{1}$ Our results would support such a management posture. 


\section{Study Limitations}

Because this is a retrospective study, inherent limitations of such studies also apply to this report. ALCAPA is an uncommon clinical condition, and large single-center series are just as uncommon. The relatively small sample size made testing of many variables in the logistic model impossible.

No consensus exists on the guidelines for postcardiotomy LVAD implantation in children. Different surgical teams have variable thresholds for LVAD implantation, a phenomenon that affects the generalizability of the study results.

\section{CONCLUSIONS}

The requirement for MCS after ALCAPA repair is best predicted by the preoperative severity of LV dysfunction and the duration of ischemia imposed during the repair. When preoperative LV dysfunction is severe (FS $<20 \%$ ), an XCT time greater than 56 minutes imposes a substantial risk of failure to wean from $\mathrm{CPB}$, leading to a requirement for postoperative MCS.

The authors thank Dr Kissinger Marfo of the Korle Bu Teaching Hospital for assistance with statistical software and literature.

\section{References}

1. del Nido PJ, Duncan BW, Mayer JE Jr, Wessel DL, LaPierre RA, Jonas RA. Left ventricular assist device improves survival in children after repair of anomalous origin of the left coronary artery from the pulmonary artery. Ann Thorac Surg. 1999;67:169-72.

2. Vouhé PR, Tamisier D, Sidi D, Vernant F, Mauriat P, Pouard P, Leca F. Anomalous left coronary artery from the pulmonary artery: results of isolated aortic reimplantation. Ann Thorac Surg. 1992;54:621-7.

3. Cochrane AD, Coleman DM, Davis AM, Brizard CP, Wolfe R, Karl TR. Excellent long-term functional outcome after an operation for anomalous left coronary artery from the pulmonary artery. J Thorac Cardiovasc Surg. 1999; 117:332-42.
4. Nasseri BA, Alexi-Meskishvili V, Nordmeyer S, et al. Predictors for the use of left ventricular assist devices in infants with anomalous left coronary artery from the pulmonary artery. Ann Thorac Surg. 2010;90:580-7.

5. Azakie A, Russell JL, McCrindle BW, et al. Anatomic repair of anomalous left coronary artery from the pulmonary artery by aortic reimplantation: early survival, patterns of ventricular recovery and late outcome. Ann Thorac Surg. 2003;75:1535-41.

6. Edwin F, Kinsley RH, Brink J, Martin G, Mamorare HM, Colsen PR. Late primary arterial switch for transposition of the great arteries with intact ventricular septum in an African population. World J Pediatr Congenital Heart Surg. 2011;2: 237-42.

7. Vouhé PR, Tamisier D, Sidi D, et al. Anomalous left coronary artery from the pulmonary artery: results of isolated aortic reimplantation. Ann Thorac Surg. 1992; 54:621-6.

8. Lambert V, Touchot A, Losay J, et al. Midterm results after surgical repair of anomalous origin of the coronary artery. Circulation. 1996;94:II38-43.

9. Lange R, Vogt M, Hörer J, et al. Long-term results of repair of anomalous origin of the left coronary artery from the pulmonary artery. Ann Thorac Surg. 2007;83: 2169-75.

10. Modi P, Suleiman MS, Reeves B, et al. Myocardial metabolic changes during pediatric cardiac surgery: a randomized study of 3 cardioplegic techniques. $J$ Thorac Cardiovasc Surg. 2004;128:67-75.

11. Hammon JW Jr, Graham TP Jr, Boucek RJ Jr, Parrish MD, Merrill WH Bender HW Jr. Myocardial adenosine triphosphate content as a measure of metabolic and functional myocardial protection in children undergoing cardiac operation. Ann Thorac Surg. 1987;44:467-70.

12. Backer CL, Hillman N, Dodge-Khatami A, Mavroudis C. Anomalous origin of the left coronary artery from the pulmonary artery: successful surgical strategy without assist devices. Semin Thorac Cardiovasc Surg Pediatr Cardiac Surg Апnи. 2000;3:165-72.

13. Buckberg GD. Update on current techniques of myocardial protection. Ann Thorac Surg. 1995;60:805-14.

14. Belli E, Roussin R, Ly M, Roubertie F, Le Bret E, Basaran M, Serraf A. Anomalous origin of the left coronary artery from the pulmonary artery associated with severe left ventricular dysfunction: results in normothermia. Ann Thorac Surg. 2010;90:856-60.

15. Dodge-Khatami A, Mavroudis C, Backer CL. Anomalous origin of the left coronary artery from the pulmonary artery: collective review of surgical therapy. Ann Thorac Surg. 2002;74:946-55.

16. Alexi-Meskishvili V, Nasseri BA, Nordmeyer S, et al. Repair of anomalous origin of the left coronary artery from the pulmonary artery in infants and children. $J$ Thorac Cardiovasc Surg. 2011;142:868-74.

17. Karl TR, Horton SB, Brizard C. Postoperative support with the centrifugal pump ventricular assist device (VAD). Semin Thorac Cardiovasc Surg Pediatr Card Surg Annu. 2006;9:83-91. 